\title{
The effect of reperfusion pressure on early outcomes after coronary artery bypass grafting
}

\author{
A randomized trial
}

\begin{abstract}
Among 60 patients randomly assigned to a reperfusion pressure of $50 \mathrm{~mm} \mathrm{Hg}$ or one of $75 \mathrm{~mm} \mathrm{Hg}$ (30 $\mathrm{mm} \mathrm{Hg}$ during the first 2 minutes in both groups) during initially hyperkalemic, controlled aortic root reperfusion after coronary artery bypass grafting, no in-hospital deaths occurred, no patient received an intraaortic balloon pump, no patient had new $Q$ waves, and creatine kinase MB release was similar in the two groups. Median interval between the beginning of reperfusion and the return of rhythmic cardiac contractions in the $50 \mathrm{~mm} \mathrm{Hg}$ group was 7 minutes; in the $75 \mathrm{~mm} \mathrm{Hg}$ group, it was 5 minutes $(P=0.1)$. The initial reactive hyperemic response was greater in the $75 \mathrm{~mm} \mathrm{Hg}$ group. There were no believable differences $(P<0.1)$ between the two groups in postoperative cardiac output, left and right atrial pressure, arterial blood pressure, and prevalence of catecholamine administration. (J THORAC Cardiovasc SuRg 1994;107:265-70)
\end{abstract}

F. Fontan, MD, ${ }^{\mathrm{a}}$ F. Madonna, MD, ${ }^{\mathrm{a}}$ D. C. Naftel, PhD, ${ }^{\mathrm{b}}$ J. W. Kirklin, MD, ${ }^{\mathrm{b}}$

E. H. Blackstone, MD, ${ }^{\mathrm{b}}$ and S. Digerness, $\mathrm{PhD},{ }^{\mathrm{b}}$ Bordeaux, France, and Birmingham, Ala.

$\mathrm{T}_{\mathrm{h}}$ host appropriate reperfusion pressure after global myocardial ischemia has been debated. This randomized clinical trial was performed to examine the outcome differences, if any, between reperfusion pressures of 50 and $75 \mathrm{~mm} \mathrm{Hg}$ during initially hyperkalemic controlled aortic root reperfusion.

\section{Patients and methods}

Patients and randomization. Sixty patients scheduled for primary coronary artery bypass grafting operation with antegrade, initially warm and then cold, hyperkalemic, enriched blood cardioplegia and warm, initially hyperkalemic, enriched controlled blood aortic root reperfusion were randomly assigned to a coronary reperfusion pressure of $50 \mathrm{~mm} \mathrm{Hg}$ ("group 50") or one of $75 \mathrm{~mm} \mathrm{Hg}$ ("group 75"). The patients were operated on by the senior author (F. F.) between March 6, 1991, and

From Hopital Cardiologique du Haut-Leveque, University of Bordeaux, Bordeaux, France, ${ }^{a}$ and the Division of Cardiothoracic Surgery, Department of Surgery, The University of Alabama Medical Center, Birmingham, Ala. ${ }^{b}$

Received for publication Dec. 2, 1992.

Accepted for publication May 24, 1993.

Address for reprints: Francis Fontan, MD, CliniqueSaint-Augustin 114 Ave. D'Ares, 33074 Bordeaux, France.

Copyright 1994 by Mosby-Year Book, Inc.

$0022-5223 / 94 \$ 1.00+.10 \quad 12 / 1 / 49085$
September 27, 1991. The random assignment of all 60 patients was done with a computer pseudorandom-number generator before the beginning of the study.

Surgical techniques. Patients were operated on through a median sternotomy. The extracorporeal circulation was established by insertion of an arterial cannula into the ascending aorta and of a single venous cannula through the right atrial appendage. A membrane oxygenator and pulsatile arterial inflow were used in all patients. The temperature of the perfusate during cardiopulmonary bypass (CPB) was $33^{\circ} \mathrm{C}$, except that the perfusion was kept normothermic until after the completion of proximal anastomoses, the first step in the operation performed before aortic crossclamping. The left ventricle was vented by a catheter (silicone rubber catheter DLP-31481; DLP, Inc., Grand Rapids, Mich.) introduced through the right superior pulmonary vein and advanced to the apex of the left ventricle. The left atrial pressure was reduced to zero or slightly negative pressure by adjustment of the amount of suction applied.

Cardioplegia and initially hyperkalemic reperfusion. Cold hyperkalemic, enriched blood was used as the cardioplegic agent (Appendix Table I). The cold cardioplegic and reperfusion solutions were delivered through a catheter (DLP 24009, which has a side arm for monitoring pressure) in the aortic root, which was isolated from the systemic circulation by an aortic crossclamp distal to the aortic root catheter. ${ }^{3}$ The initial dose of cold cardioplegic solution was $450 \mathrm{ml} / \mathrm{m}^{2}$ body surface area and was given at an aortic root pressure of $50 \mathrm{~mm} \mathrm{Hg}$. A second dose of $75 \mathrm{ml} / \mathrm{m}^{2}$ (Appendix Table I) was administered after approximately 30 minutes. Because all proximal venous anastomoses 
Table I. Cardiac index $\left(L \cdot \min \cdot \mathrm{m}^{-2}\right)$ after coronary artery bypass grafting according to reperfusion pressure

\begin{tabular}{|c|c|c|c|c|c|c|}
\hline \multirow[b]{2}{*}{ Reperfusion pressure } & \multicolumn{2}{|c|}{$\begin{array}{l}30 \text { minutes } \\
\text { after } C P B\end{array}$} & \multicolumn{2}{|c|}{$\begin{array}{c}\text { Evening of } \\
\text { operation }\end{array}$} & \multicolumn{2}{|c|}{ Postop. day 1} \\
\hline & $\mathrm{n}$ & Mean $\pm S E$ & $\mathrm{n}$ & Mean $\pm S E$ & $\mathrm{n}$ & Mean $\pm S E$ \\
\hline $50 \mathrm{~mm} \mathrm{Hg}$ & 30 & $3.1 \pm 0.16$ & 28 & $3.0 \pm 0.13$ & 28 & $3.2 \pm 0.12$ \\
\hline $75 \mathrm{~mm} \mathrm{Hg}$ & 30 & $3.2 \pm 0.13$ & 30 & $3.1 \pm 0.12$ & 29 & $3.0 \pm 0.09$ \\
\hline$P$ value by $t$ test & & 0.7 & & 0.7 & & 0.14 \\
\hline
\end{tabular}

were performed before aortic crossclamping, the second dose of cardioplegic solution perfused coronary arteries to which vein grafts had already been attached.

The reperfusion after the period of global myocardial ischemia consisted of an initial $500 \mathrm{ml}$ normothermic, hyperkalemic, enriched reperfusate at specified pressures. Thereafter the reperfusate was unmodified blood from the oxygenator. Reperfusion into the isolated aortic root was continued untilstrong and regular cardiac contractions occurred. Only then was the aortic crossclamp removed, with appropriate precautions against air embolization. The clamps on the internal mammary artery pedicles were removed immediately after the initially hyperkalemic phase of reperfusion.

In all patients during the first 2 minutes of reperfusion, the reperfusion pressure was $30 \mathrm{~mm} \mathrm{Hg}$. This practice has been followed throughout our clinical experience with controlled reperfusion, ${ }^{3,4}$ because of early experimental work (Shangyi J, Hongxi S, Gongshong L. Unpublished data, 1987) $)^{5,6}$; random assignment of patients to low and high initial reperfusion pressures did not seem justifiable. After 30 minutes, the aortic root and therefore the coronary perfusion pressures were $50 \mathrm{~mm} \mathrm{Hg}$ in the patients randomly assigned to "group 50 " and $75 \mathrm{~mm} \mathrm{Hg}$ in those randomly assigned to "group 75." The pressure value of $75 \mathrm{~mm} \mathrm{Hg}$ was chosen because it is the usual diastolic blood pressure in adults.

Measurements. The rate of coronary blood flow was the rate of controlled aortic root reperfusion, as continuously measured by the calibrated flowmeter of the roller pumps, which were adjusted to be just occlusive. The aortic valve was competent in all patients. The aortic root (coronary perfusion) pressure was continuously measured through the side arm of the aortic root catheter. Coronary resistance was computed by dividing the aortic root pressure by coronary blood flow, and is expressed as millimeters of mercury per milliliter per minute.

Cardiac indexes $\left(\mathrm{L} \cdot \mathrm{min}^{-1} \cdot \mathrm{m}^{-2}\right)$ were measured by thermodilution 20 to 30 minutes after the end of CPB, 3 to 4 hours after return of the patient to the intensive care unit, and the next morning. The methods for this and for the other measurements are the same as in a previous study from Hopital Cardiologique du Haut-Leveque. ${ }^{4}$

\section{Results}

Results of random assignment. The two groups that resulted from the random assignment were similar with regard to patient characteristics (Appendix Table II) and surgical variables. One or more arterial grafts were used in $30(100 \%)$ of the patients in "group 50" and in 28 $(93 \%)$ of those in "group 75" $\left(P\left[x^{2}\right]=0.15\right)$; the left internal mammary (internal thoracic) artery was used in
28 "group 50" patients (93\%) and 26 "group 75" patients $\left(87 \%,\left(P\left[\chi^{2}\right]=0.4\right)\right.$ and the right internal mammary artery was used in six "group 50" $(20 \%)$ and eight "group 75 " patients $(27 \%)\left(P\left[\chi^{2}\right]=0.5\right)$. Vein grafts were used in 27 "group 50" patients (90\%) and 28 "group 75" patients $(93 \%)$.

The $\mathrm{pH}$ of the initial reperfusate was $7.61 \pm 0.015$ (standard error [SE]) in "group 50" and 7.62 \pm 0.014 in "group 75" $\left(P\left[\chi^{2}\right]=0.6\right)$. Carbon dioxide tensions were $22 \pm 2.3 \mathrm{~mm} \mathrm{Hg}$ in "group 50" and $20 \pm 1.1 \mathrm{~mm} \mathrm{Hg}$ in "group 75" $\left(P\left[\chi^{2}\right]=0.3\right)$, oxygen tensions were $139 \pm 6.2$ and $141 \pm 5.6 \mathrm{~mm} \mathrm{Hg}\left(P\left[\chi^{2}\right]=0.8\right)$, hemoglobin concentrations were $7.7 \pm 0.23$ and $7.7 \pm 0.20$ $\mathrm{gm} \cdot \mathrm{dl}^{-1}\left(P\left[\chi^{2}\right]=0.9\right)$, sodium concentrations were $120 \pm 1.4$ and $118 \pm 1.3 \mathrm{mmol} \cdot \mathrm{L}^{-1}\left(P\left[\chi^{2}\right]=0.3\right)$, potassium concentrations were $11.8 \pm 1.19$ and $12.2 \pm 1.22 \mathrm{mmol} \cdot \mathrm{L}^{-1}\left(P\left[\chi^{2}\right]=0.8\right)$, ionized calcium concentrations were $0.95 \pm 0.026$ and $0.94 \pm 0.019$ $\mathrm{mmol} \cdot \mathrm{L}^{-1}\left(P\left[\chi^{2}\right]=0.7\right)$, and glucose levels were $55 \pm 2.7$ and $54 \pm 2.4 \mathrm{mmol} \cdot \mathrm{L}^{-1}\left(P\left[\chi^{2}\right]=0.6\right)$. The median durations of the single period of global myocardial ischemia were 43 in "group 50" and 42 minutes in "group 75"; the 10th, 25th, 75th, and 90th percentiles were $27,34,51$, and 58 minutes in "group 50" and 28, 34, 54 , and 60 minutes in "group 75" $(P[$ Wilcoxon $]=0.8)$.

Deaths and cardiac events. No in-hospital deaths occurred in either group. No patient received an intraaortic balloon pump. Catecholamines were administered to one patient in "group 50" and two in "group 75" $\left(P\left[\chi^{2}\right]=\right.$ $0.6)$. Cardiac index was slightly higher in "group 75 " in the operating room 30 minutes after repair and slightly higher in "group 50" the next morning, but all differences could have resulted from chance alone (Table I).

After discontinuation of CPB, mean left atrial pressures among the 60 patients in the two groups were $8.6 \pm 0.69,6.7 \pm 0.56$, and $7.2 \pm 0.57 \mathrm{~mm} \mathrm{Hg}$ in the operating room 30 minutes after cessation of $\mathrm{CPB}$, later that day, and on the morning of postoperative day 1 , respectively. Differences between the groups were trivial $(P[t$ test $]=0.5,0.3$, and 0.9 , respectively). Mean right atrial pressures at the three times in the 60 patients were $7.1 \pm 0.46,6.5 \pm 0.49$, and $7.5 \pm 0.55$, respectively; pressures were similar in "group 50" and "group 75" 


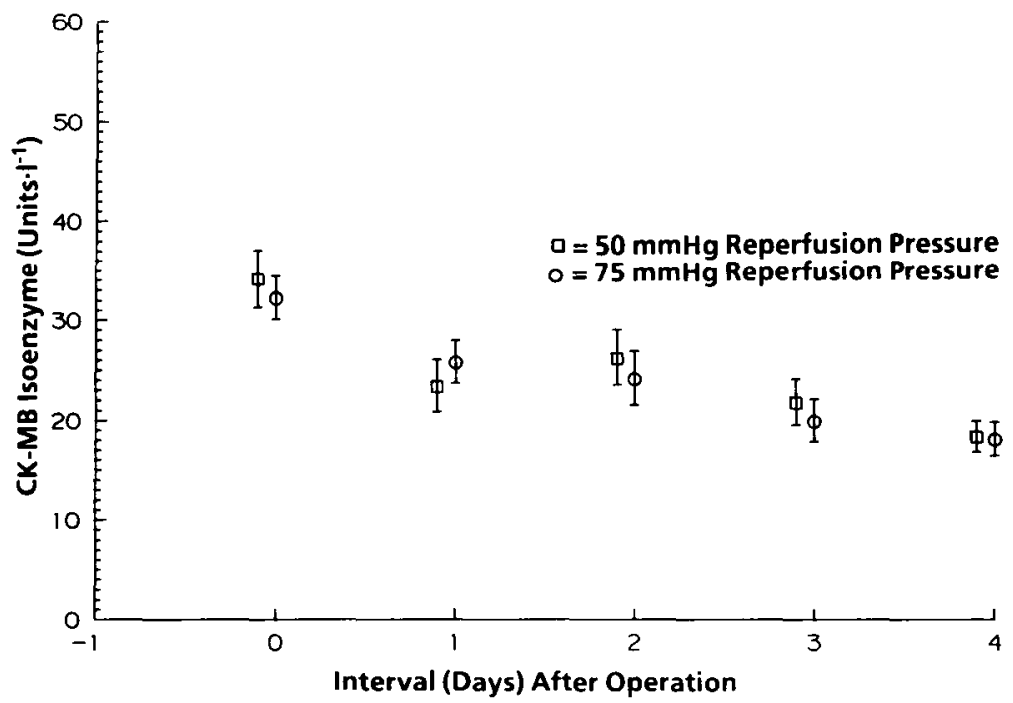

Fig. 1. Creatine kinase $\mathrm{MB}(C K-M B)$ isoenzyme levels on the evening of day of operation (day 0 ) and in the morning of the first, second, third, and fourth postoperative days (days 1,2,3, and 4). Vertical bars represent SE; where SEs of pairs are not overlapping, the differences are unlikely to be due to chance alone.

except on the evening of operation, when the mean right atrial pressure was $5.6 \pm 0.54 \mathrm{~mm} \mathrm{Hg}$ in "group 50" and $7.4 \pm 0.80$ in "group 75" $(P[t$ test $]=0.07)$.

At the same three times, values in the two groups were similar $(P[t$ test $]>0.1)$ for arterial $\mathrm{pH}$ (except in the operating room, when it was $7.41 \pm 0.010$ in "group 75" and $7.43 \pm 0.012$ in "group 50," $P[t$ test $]=0.13$ ), arterial carbon dioxide tension (except in the operating room, when it was $41 \pm 1.2 \mathrm{~mm} \mathrm{Hg}$ in "group 75" and $37 \pm 0.9$ in "group 50," $P[t$ test $]=0.006)$, arterial oxygen tension, hematocrit value, and mixed venous (right atrial) oxygen saturation and tension.

Creatine kinase MB isoenzyme release was similar in the two groups, as evidenced by similarity in the serum levels (Fig. 1). No patients $(0 \%, 70 \%$ confidence limits [CL] $0 \%$ to 3\%) in either group had new $Q$ waves.

No patient had ventricular fibrillation after CPB. Atrial fibrillation developed in $17(29 \%, 70 \%$ CL $22 \%$ to $36 \%$ ) of the 59 patients who had not had it before operation; and the prevalence was similar in the two groups $\left(P\left[\chi^{2}\right]=0.6\right)$.

Coronary flow and resistance. The 10th, 25th, 50th, 75th, and 90th percentiles of the duration of the hyperkalemic phase of reperfusion were 1.5, 2, 2.5, 3, and 4 minutes, respectively, in "group 50," and 2, 2, 2.5, 2.5, and 3 minutes, respectively, in "group 75" ( $P$ [Wilcoxon] $=0.8$ ). During the first 2 minutes of reperfusion, coronary flow was the same $(P[$ Wilcoxon $]=0.8)$ in both groups (see later Fig. 3, $A$ ).

The median interval between the beginning of con- trolled aortic root reperfusion and the return of rhythmic ventricular contractions was shorter in "group 75" than in "group 50" (Fig. 2); in each group two patients (7\%) required cardioversion of ventricular fibrillation before rhythmic contractions began. Likewise, the interval between the beginning of reperfusion and the removal of the aortic crossclamp (and shortly thereafter discontinuance of CPB) was shorter in "group 75" (the 10th, 25th, 50th, 75th, and 90th percentiles were 5.0, 6.0, 8.0, 12.2, and 14.9 minutes, respectively) than in "group 50" (the 10 th, 25th, 50th, 75th, and 90th percentiles were 8,9 , $11.5,13$, and 15.9 minutes, respectively; $P[$ Wilcoxon] $=0.0008$ ). The interval between the termination of the hyperkalemic phase of reperfusion and the first rhythmic contraction was shorter in "group 75" than in "group 50" $(P[$ Wilcoxon $]=0.05)$.

After the first 2 minutes, the coronary reactive hyperemic flow response was greater in "group 75" than in "group 50" (Fig. 3, $A$ ). The differences in coronary resistance were minimal during the first $4 \frac{1}{2} 2$ minutes of reperfusion, but thereafter resistance became progressively higher in "group 50" and increased only mildly in "group 75" (Fig. 3, B).

Because some hearts began to beat at about 5 minutes after the start of controlled aortic root reperfusion, the pressure-flow relationships during reperfusion in nonbeating (electromechanically quiescent) hearts and beating hearts could be examined separately. In "group 75" within 1.5 minutes of the start of beating, flow tended to be higher in the electromechanically quiescent hearts 

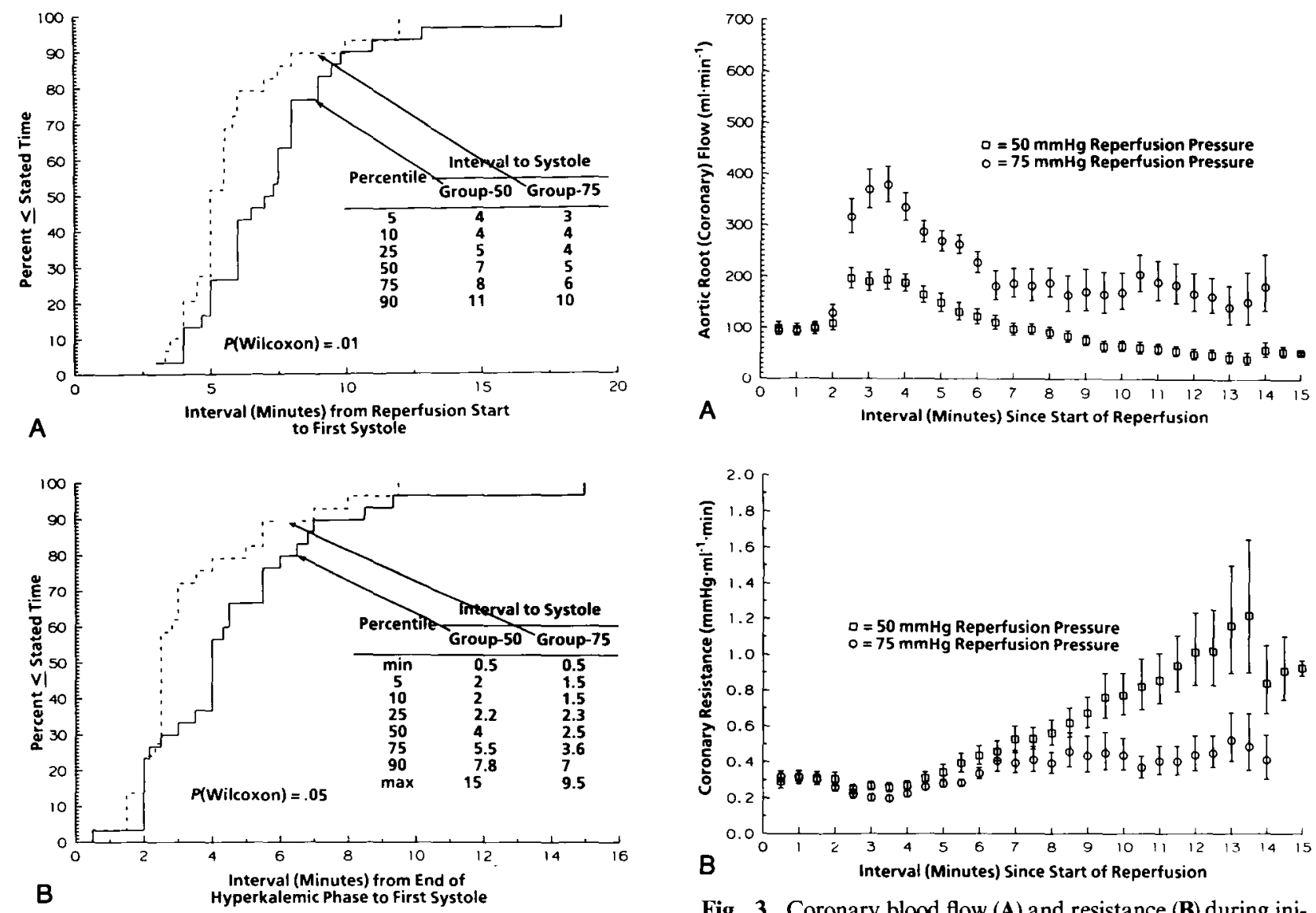

Fig. 2. Cumulative frequency distribution of interval in minutes between start of reperfusion and first systole (A) and interval in minutes between end of hyperkalemic phase of reperfusion and first systole (B). min, Minimum; max, maximum.

than in the beating hearts, but these differences could have been caused by chance alone (Fig. 4). The opposite relationship pertained in "group 50," with flow being lower in the quiescent hearts (Fig. 4).

\section{Discussion}

Critique of the study. The preoperative patient and surgical characteristics in the two groups were well matched by the randomization process. The patients in this study were in general patients at good risk who were undergoing elective coronary artery bypass grafting, although eight patients had unstable angina. Hospital mortality rates in general are low for such patients, and there were no deaths in this group of 60 patients or in the group of 160 patients in the previous randomized trial $(0 \%$ of 220 patients, $70 \%$ CL $0 \%$ to $0.9 \%$ ). ${ }^{2}$ The study therefore does not test the efficacy of the two protocols in a

Fig. 3. Coronary blood flow (A) and resistance (B) during initially hyperkalemic, controlled aortic root reperfusion after global myocardial ischemia for coronary artery bypass grafting. In both groups, reperfusion pressure was $30 \mathrm{~mm} \mathrm{Hg} \mathrm{during} \mathrm{the} \mathrm{first}$ 2 minutes. Vertical bars represent SE.

group of seriously ill patients, or in a group in which many of the patients had ventricular hypertrophy or chronic heart failure.

The power of the study was inadequate for detecting small differences in the outcome events. In this study, however, small differences would be of little clinical importance, so this is not considered a serious flaw.

Previous studies. Most previous studies in animal models have supported the hypothesis that myocardial edema and damage from reperfusion after global myocardial ischemia, particularly in hearts that are hypertrophied, are minimized when the reperfusion pressure is kept low $(<50 \mathrm{~mm} \mathrm{Hg}$ ) during the first few minutes of reperfusion. ${ }^{5-9}$ The hypothesis is that the coronary endothelial cells are particularly vulnerable to pressure damage during that period. ${ }^{6} \mathrm{We}$ accepted that hypothesis and 
considered testing it in this clinical trial to be inappropriate.

Studies in animal models have given conflicting results as to optimal reperfusion pressure after the first few minutes of reperfusion. Few previous studies have used a low reperfusion pressure initially. The use of this initial low pressure in this study may have minimized differences that would otherwise have appeared with the two different reperfusion pressures. Okamoto and colleagues ${ }^{5}$ suggested from their studies that reperfusion pressures greater than $50 \mathrm{~mm} \mathrm{Hg}$ produce important myocardial edema. Other studies in animal models have shown that low reperfusion pressures ( $<75$ to $100 \mathrm{~mm} \mathrm{Hg}$ ) inadequately reperfuse the endocardial layer of the myocardium and inhomogeneously reperfuse much of the rest of the myocardium, particularly in hypertrophied ventricles. ${ }^{10,11}$ Rabinov and colleagues ${ }^{11}$ found lesser initial reactive hyperemia with low reperfusion pressure after global myocardial ischemia, just as in this study in human beings. The relationship between coronary perfusion pressure and flow appears to be continuous but nonlinear. ${ }^{10}$

Inferences from the study. In the circumstances of this study, reperfusion pressures of 50 and $75 \mathrm{~mm} \mathrm{Hg}$ after the first 2 minutes are safe and effective. A believable and potentially important difference between the two reperfusion pressure protocols is the shorter interval between the beginning of controlled aortic root reperfusion and the resumption of cardiac contractions in "group 75 " (see Fig. 2).

Cold blood cardioplegia and initially hyperkalemic controlled aortic root reperfusion are simple to use, provide excellent surgical conditions, and in patients such of the type entered into this study and the previous study result in minimal myocardial damage and excellent cardiac performance postoperatively. ${ }^{4}$

Implications regarding the fundamental phenomena of reperfusion. The earlier resumption of rhythmic ventricular contractions in "group 75" (whether measured from the beginning of reperfusion or from the termination of the hyperkalemic phase) leads to the speculation that myocytes and specialized cells for conduction are more generously and homogeneously provided with oxygen and substrate and rid of metabolites with the higher perfusion pressure than with one of $50 \mathrm{~mm} \mathrm{Hg}$. This speculation is supported by the higher coronary blood flow and lower coronary resistance after the first 2 minutes in "group 75" than in "group 50" (Fig. 3). The advantages of a higher reperfusion pressure may be even greater in hypertrophied hearts and failing hearts.

No data directly relating to myocardial edema were
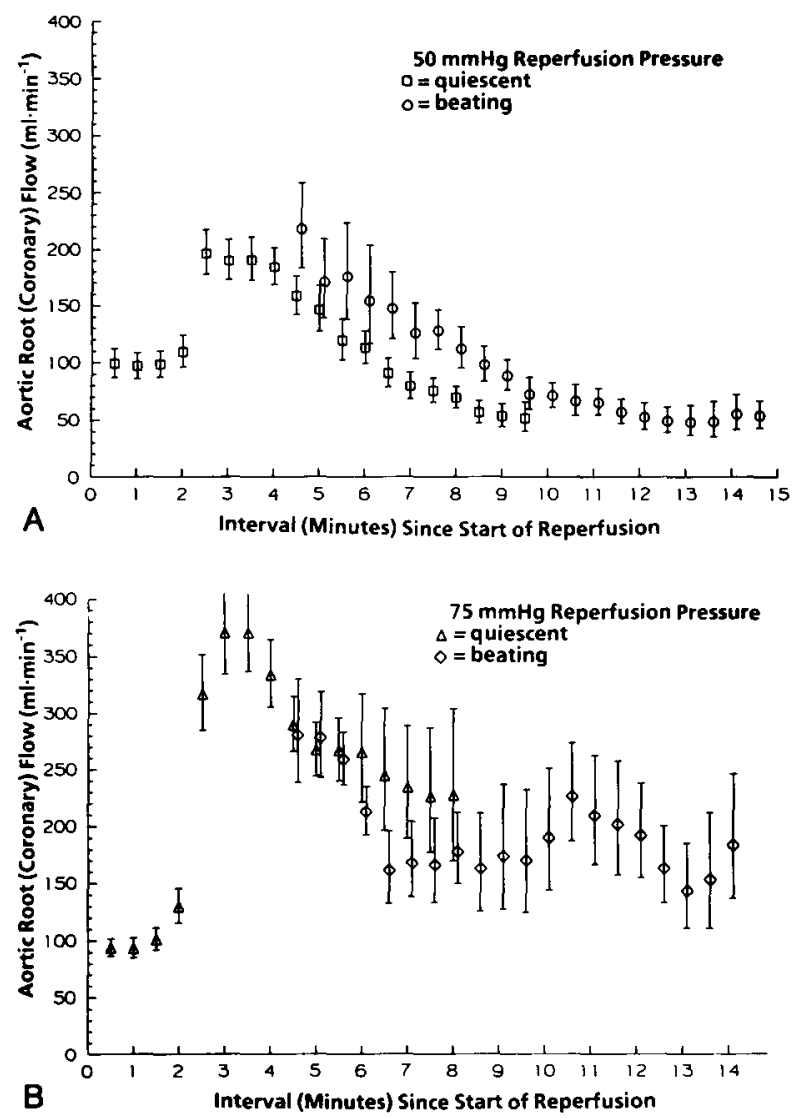

Fig. 4. Coronary blood flow during initially hyperkalemic controlled aortic root reperfusion, according to whether the heart was electromechanically quiescent or beating. A, "Group 50"; B, "group 75." Reperfusion pressure was $30 \mathrm{~mm} \mathrm{Hg}$ during the first 2 minutes in both groups. Vertical bars represent $\mathrm{SE}$.

obtained. However, the similar postoperative cardiac outputs and left atrial pressures in the two groups lead to the speculation that left ventricular distensibility, and thus myocardial water content, were similar in the two groups.

The similarity of the coronary resistance in the two groups between 2 and $4 \frac{1}{2}$ minutes after the start of reperfusion (Fig. 3, $B$ ). Invites the speculation that autoregulation of flow by variable resistance (such as occurs normally) generally does not occur during this early phase of reperfusion after hypothermic global myocardial ischemia of about 50 minutes. The differences in coronary resistance between "group 50" and "group 75" after this time would thus result from the return of coronary autoregulation, at least to some degree. One may speculate that the considerable rise in coronary resistance seen after about $4 \frac{1}{2}$ minutes in "group 50" may be disadvantageous 
to oxygen delivery and result in additional myocardial damage.

\section{REFERENCES}

1. Buckberg GD. Antegrade/retrograde blood cardioplegia to ensure cardioplegic distribution: operative techniques and objectives. J Cardiac Surg 1989;4:216-38.

2. Kirklin JW, Barratt-Boyes BG. Cardiac surgery. 2nd ed. New York: Churchill Livingstone, 1993: Fig. 3-12.

3. Digerness SB, Kirklin JW, Naftel DC, Blackstone EH,

Appendix Table I. Details of the cardioplegic solutions and their delivery

\begin{tabular}{lc}
\hline \multicolumn{1}{c}{$\begin{array}{c}\text { Asanguineous cardioplegic } \\
\text { additive }\end{array}$} & Amount $(\mathrm{ml})$ \\
\hline Potassium chloride $(2$ & 7.5 \\
mol $/ \mathrm{L})$ & \\
THAM $(0.3 \mathrm{~mol} / \mathrm{L})$ & 113 \\
CPD & 113 \\
Aspartate $(0.225 \mathrm{~mol} / \mathrm{L})$ & 125 \\
$\quad$ and glutamate $(0.225$ & \\
mol $/ \mathrm{L})$ & \\
Dextrose $50 \%$ in water & 20 \\
Dextrose $5 \%$ in water & 100 \\
Total & 478.5 \\
\hline
\end{tabular}

$T H A M$, Tris(hydroxymethyl) aminomethane; $C P D$, anticoagulant citrate phosphate dextrose solution NDC 0074-1967-04 (Abbott Laboratories, Abbott Park,

Ill.). Aspartate and glutamate powder prepared by Ajinomoto (Teaneck, N.J.). Addition of $15 \mathrm{ml}$ of potassium chloride $(2 \mathrm{~mol} / \mathrm{L})$ to solution in the operating room results in a potassium concentration in the reperfusate of $0.022 \mathrm{~mol} / \mathrm{L}$; this concentration was used for initial dose of cold hyperkalemic blood cardioplegia. No modification results in a potassium concentration in the reperfusate of 0.010 $\mathrm{mol} / \mathrm{L}$; this dose was used for subsequent adminis trations of cold cardioplegia and during warm, initially hyperkalemic phase of reperfusion. Asanguineous additive solution is mixed (1:4) with blood from oxygenator in dual-boot pump used for delivery of then sanguineous cardioplegic solution. ${ }^{1,2}$
Kirklin JK, Samuelson PN. Coronary and systemic vascular resistance during reperfusion after global myocardial ischemia. Ann Thorac Surg 1988;46:447-54.

4. Fontan F, Madonna F, Naftel DC, Kirklin JW, Blackstone EH, Digerness S. Modifying myocardial management in cardiac surgery: a randomized trial. Eur J Cardiothorac Surg 1992;6:127-37.

5. Okamoto F, Allen BS, Buckberg GD, Bugyi H, Leaf J. Studies of controlled reperfusion after ischemia. XIV. Reperfusion conditions: importance of ensuring gentle versus sudden reperfusion during relief of coronary occlusion. J Thorac Cardiovasc SuRg 1986;92:613-20.

6. Sawatari K, Kadoba K, Bergner KA, Mayer JE Jr. Influence of initial reperfusion pressure after hypothermic cardioplegic ischemia on endothelial modulation of coronary tone in neonatal lambs: impaired coronary vasodilator response to acetylcholine. J THORAC CARdiovaSC SURG 1991;101:777-82.

7. Kirklin JW, Barratt-Boyes BG. Cardiac surgery. 2nd ed. New York: Churchill Livingstone, 1993:138.

8. Muller C, Isselhard W, Sturz J, et al. Pressure-controlled reperfusion improves postischemic recovery of LV-hypertrophied rat hearts. Angiology 1989;40:574-80.

9. Gunnes S, Ytrehus K, Srlie D. Effects of initial reperfusion temperature and pressure after prolonged cardioplegic ischemic arrest: a metabolic and functional study in rat hearts. Scand J Thorac Cardiovasc Surg 1990;24:135-9.

10. Aldea GS, Austin RE, Flynn AE, Coggins DL, Hasseini W, Hoffman JIE. Heterogeneous delivery of cardioplegic solution in the absence of coronary artery disease. J THORAC CardiovasC SuRg 1990;99:345-53.

11. Rabinov M, Newman M, Smolich JJ, Rosenfeldt FL. Adverse effects of low-pressure reperfusion after hypothermic cardioplegia in normal and hypertrophic hearts. J Thorac CardiovasC SURg 1991;102:695-706.

Appendix Table II. Preoperative patient characteristics

\begin{tabular}{|c|c|c|c|c|c|c|c|c|c|}
\hline \multirow[b]{2}{*}{$\begin{array}{c}\text { Patient } \\
\text { characteristics }\end{array}$} & \multicolumn{4}{|c|}{$50 \mathrm{~mm} \mathrm{Hg}$} & \multicolumn{4}{|c|}{$75 \mathrm{~mm} \mathrm{Hg}$} & \multirow[b]{2}{*}{$\begin{array}{c}P \text { value } \\
\left(\chi^{2}\right)\end{array}$} \\
\hline & $\mathrm{n}^{*}$ & No. & $\%$ & $\begin{array}{c}70 \% C L \\
(\%)\end{array}$ & $\mathrm{n}^{*}$ & No. & $\%$ & $\begin{array}{c}70 \% C L \\
(\%)\end{array}$ & \\
\hline Female sex & 30 & 6 & 20 & $12-30 \%$ & 29 & 5 & 17 & $10-28$ & 0.8 \\
\hline PAC 1 & 27 & 1 & 3 & $0.5-12 \%$ & 27 & 4 & 15 & $8-25$ & 0.16 \\
\hline PAC 2 & 27 & 11 & 41 & $30-53$ & 27 & 9 & 33 & $23-45$ & 0.6 \\
\hline PAC 3 & 27 & 13 & 48 & $37-60$ & 27 & 13 & 48 & $37-60$ & 1 \\
\hline PAC 4 & 27 & 2 & 7 & $2-17$ & 27 & 1 & 3 & $0.5-12$ & 0.6 \\
\hline Unstable angina & 30 & 3 & 10 & $4-19$ & 29 & 2 & 7 & $2-16$ & 0.7 \\
\hline ID diabetes & 30 & 1 & 3 & $0.5-12$ & 29 & 0 & 0 & $0-6$ & 0.3 \\
\hline Hypertension & 30 & 19 & 63 & $52-73$ & 29 & 14 & 48 & $37-59$ & 0.2 \\
\hline History of MI & 30 & 11 & 37 & $27-48$ & 29 & 13 & 45 & $34-56$ & 0.5 \\
\hline Standard preop. treatment & 30 & 29 & 37 & $89-99$ & 29 & 28 & 97 & $89-99$ & 0.9 \\
\hline Nitrates & 30 & 20 & 67 & $56-76$ & 29 & 25 & 86 & $76-93$ & 0.08 \\
\hline Beta blockers & 30 & 11 & 37 & $27-48$ & 29 & 16 & 55 & 44-66 & 0.15 \\
\hline Calcium antagonists & 30 & 25 & 83 & $73-91$ & 29 & 15 & 52 & $41-63$ & 0.009 \\
\hline Intensive preop. treatment & 30 & 5 & 17 & $9-27$ & 29 & 3 & 10 & $5-20$ & 0.5 \\
\hline IV nitrates & 30 & 5 & 17 & $9-27$ & 29 & 3 & 10 & $5-20$ & 0.5 \\
\hline IV heparin & 30 & 2 & 7 & $2-15$ & 29 & 3 & 10 & $5-20$ & 0.5 \\
\hline
\end{tabular}

$P A C$, Preoperative angina class (Canadian Heart Association angina class); $I D$, insulin-dependent; $I V$, intravenous; $M I$, myocardial infarction.

*The $n$ is less than 30 when the values for one or more patients were unknown.

No patient was receiving catecholamines or received an intraaortic balloon pump before operation. 